\title{
ВMJ Global Health Improving quality of care during childbirth in primary health centres: a stepped-wedge cluster-randomised trial in India
}

Ramesh Agarwal, ${ }^{1}$ Deepak Chawla, ${ }^{2}$ Minakshi Sharma, ${ }^{3}$ Shyama Nagaranjan, ${ }^{4}$ Suresh K Dalpath, ${ }^{5}$ Rakesh Gupta, ${ }^{5}$ Saket Kumar, ${ }^{5}$ Saumyadripta Chaudhuri, ${ }^{1}$ Premananda Mohanty, ${ }^{3}$ Mari Jeeva Sankar, ${ }^{1}$ Krishna Agarwal, ${ }^{6}$ Shikha Rani, ${ }^{7}$ Anu Thukral, ${ }^{1}$ Suksham Jain, ${ }^{2}$ Chandra Prakash Yadav, ${ }^{8}$ Geeta Gathwala, ${ }^{9}$ Praveen Kumar, ${ }^{10}$ Jyoti Sarin, ${ }^{11}$ Vishnubhatla Sreenivas, ${ }^{12}$ Kailash C Aggarwal, ${ }^{13}$ Yogesh Kumar, ${ }^{11}$ Pradip Kharya, ${ }^{14}$ Surender Singh Bisht, ${ }^{15}$ Gopal Shridhar, ${ }^{16}$ Raksha Arora, ${ }^{17}$ Kapil Joshi, ${ }^{18}$ Kapil Bhalla, ${ }^{9}$ Aarti Soni, ${ }^{19}$ Sube Singh, ${ }^{5}$ Prischillal Devakirubai, ${ }^{16}$ Ritu Samuel, ${ }^{16}$ Reena Yadav, ${ }^{20}$ Rajiv Bahl, ${ }^{21}$ Vijay Kumar, ${ }^{3}$ Vinod Kumar Paul, ${ }^{1}$ for the QI Haryana Study Collaboration

To cite: Agarwal R, Chawla D, Sharma M, et al. Improving quality of care during childbirth in primary health centres: a stepped-wedge cluster-randomised trial in India. BMJ Glob Health 2018;3:e000907. doi:10.1136/ bmjgh-2018-000907

Handling editor Valery Ridde

- Additional material is published online only. To view please visit the journal online (http://dx.doi.org/10.1136/ bmjgh-2018-000907).

Received 16 April 2018 Revised 14 August 2018 Accepted 14 August 2018

\section{Check for updates}

(c) Author(s) (or their employer(s)) 2018. Re-use permitted under CC BY-NC. No commercial re-use. See rights and permissions. Published by BMJ.

For numbered affiliations see end of article.

\section{Correspondence to}

Dr Vijay Kumar;

1940kumarv@gmail.com and Professor Vinod Kumar Paul; vinodkpaul@gmail.com

\section{ABSTRACT}

Background Low/middle-income countries need a largescale improvement in the quality of care $(\mathrm{QOC})$ around the time of childbirth in order to reduce high maternal, fetal and neonatal mortality. However, there is a paucity of scalable models.

Methods We conducted a stepped-wedge clusterrandomised trial in 15 primary health centres $(\mathrm{PHC})$ of the state of Haryana in India to test the effectiveness of a multipronged quality management strategy comprising capacity building of providers, periodic assessments of the PHCs to identify quality gaps and undertaking improvement activities for closure of the gaps. The 21-month duration of the study was divided into seven periods (steps) of 3 months each. Starting from the second period, a set of randomly selected three PHCs (cluster) crossed over to the intervention arm for rest of the period of the study. The primary outcomes included the number of women approaching the PHCs for childbirth and 12 directly observed essential practices related to the childbirth. Outcomes were adjusted with random effect for cluster (PHC) and fixed effect for 'months of intervention'.

Results The intervention strategy led to increase in the number of women approaching PHCs for childbirth (26 vs 21 women per PHC-month, adjusted incidence rate ratio: $1.22 ; 95 \% \mathrm{Cl} 1.17$ to 1.28$)$. Of the 12 practices, 6 improved modestly, 2 remained near universal during both intervention and control periods, 3 did not change and 1 worsened. There was no evidence of change in mortality with a majority of deaths occurring either during referral transport or at the referral facilities.

Conclusion A multipronged quality management strategy enhanced utilisation of services and modestly improved key practices around the time of childbirth in PHCs in India. Trial registration number CTRI/2016/05/006963.
Key questions

What is already known?

- The childbirth and first 24 hours after birth contribute to nearly half of the total stillbirths and maternal and neonatal deaths.

- Improvement in quality of care during childbirth and postnatal period is necessary to meet the Sustainable Development Goals.

What are the new findings?

- A provider-led multipronged quality management programme with external facilitation was successful in improving key care practices during childbirth and immediate postnatal period.

- A large number of deficits in the quality of care were due to structural issues which need system strengthening and are difficult to address by healthcare providers themselves.

What do the new findings imply?

- Healthcare providers at small facilities should be trained in the methods of monitoring and addressing quality gaps and they should be fully supported with needed resources to identify and address the lacunae in quality of care.

\section{INTRODUCTION}

Despite significant decline in maternal and under-5 child deaths over last two decades, 275000 maternal death and 5.9 million under-5 deaths including 2.7 million neonatal deaths still occur every year, over $90 \%$ of them in the low/middle-income countries (LMIC). ${ }^{12}$ Due to slower decline of neonatal deaths, its contribution to under-5 deaths has 
increased from $36 \%$ in 1990 to $46 \%$ in $2015 .{ }^{13}$ Additionally, a burden of approximately 2.1 million stillbirths every year, unnoticed so far, has also become a major concern. ${ }^{3}$ The childbirth and first 24 hours thereafter is the most critical period as nearly half of total stillbirths and maternal and neonatal deaths occur during this period. $^{45}$

Increase in institutional deliveries in India from $38.7 \%$ in 2005-2006 to $78.9 \%$ in 2015-2016 has not translated into commensurate gains in maternal and neonatal survival but has largely shifted the mortality burden from the community to the facilities. ${ }^{6-8}$ This has been attributed to low quality of care (QoC) in the facilities and improving the QoC in addition to universal coverage of evidence-based interventions has therefore been identified as a key strategy to achieve Sustainable Development Goals of significantly reducing maternal, fetal and neonatal mortality by $2030 .{ }^{9}$ Improved QoC is expected to save nearly 113000 maternal deaths, 531 000 stillbirths and 1325000 neonatal deaths every year globally. ${ }^{10}$

Most of the evidence on improvement in QoC has emanated from high-income countries, which have strong and functional health systems. Systematic reviews demonstrate dearth of good-quality evidence on interventions, which can improve QoC of maternal and newborn health in LMICs with weaker health systems. ${ }^{10}$ Recently, a large cluster-randomised trial (BetterBirth study) undertaken in Uttar Pradesh state of India focused on implementation of coaching-based WHO safe childbirth checklist (BetterBirth checklist) as a tool to drive QoC in small facilities. ${ }^{11}$ The trial reported a modest improvement in adherence to essential practices around the time of childbirth but no change in perinatal deaths, maternal deaths or maternal severe complications.

The QoC is a multifaceted concept which envisions that the clients receive good-quality evidence-based care (provision of care) and are also treated well (experience of care). Providing good QoC which is safe, timely, effective, efficient, equitable and patient centred requires a robust health system. Improvement in healthcare processes needs 'structure' to be in place in the form of skilled and committed human resource, infrastructure, information system, equipment and supplies, financing, and leadership/governance. The Donabedian and WHO models emphasise the importance of both robust 'structure' and 'processes' in order to achieve desirable health outcomes. ${ }^{612}$

We hypothesised that quality management activities driven by facility teams with external facilitation and comprising activities to build capacity of the providers, regular review of key inputs and outcomes to identify gaps and closing those gaps through facility teams' improvement efforts will increase the uptake of essential practices around the time of childbirth in primary health centres (PHC). The improved QoC would enhance the faith of community and families, which would improve utilisation of the PHC services.

\section{METHODS}

\section{Context and study settings}

We conducted this stepped-wedge (SW) cluster-randomised trial in 15 PHCs of districts Ambala and Yamunanagar in the state of Haryana of India between 1 February 2014 and 31 October 2015. Despite being economically well off with per capita income of nearly $\$ 2000$, the health indices of Haryana do not match its economic prowess. ${ }^{13}$ The crude birth rate $(21.3 / 1000)$, maternal mortality ratio (146/100 000 live births) and under-5 mortality rate (51/1000 live births) are high and comparable to those of India (online supplementary table S1).${ }^{14-16}$ However, the state has good road connectivity and the district hospital $(\mathrm{DH})$ can be reached approximately in an hour from the PHCs. The PHCs provide round-the-clock basic obstetric care and are typically staffed by medical officers (MO; $n=1-2$; one of them being female $\mathrm{MO}$ as some patients prefer to be delivered by women) and nurses $(n=3-4)$. There is no provision for blood transfusion, operative delivery, manual removal of placenta or care of small or sick neonates. The State provides free ambulance service to transport women or newborn infants needing referral care.

We selected 15 of 30 PHCs of the two districts based on the number of deliveries being more than median annual number of deliveries (99 or more in a year) in the PHCs. The study was undertaken with active involvement of functionaries of National Health Mission (NHM), state government and $\mathrm{DH}$.

\section{Design and intervention}

We employed SW cluster-randomised design to test our hypothesis. SW design offers pragmatic advantage of staggered rolling out of intervention, avoids dilemma of having a control group, is statistically more powerful and better controls for the secular trend than a beforeand-after study. ${ }^{17} 18$ The 21-month duration of the study was divided into seven periods (steps) of 3 months each (online supplementary figure S1). During the first 3 months (period 1), none of the PHCs initiated intervention. From period 2 to period 5 , a set of randomly selected three PHCs (which constituted a cluster for the study) initiated intervention in each period such that three PHCs were receiving intervention in period 2 , six in period 3 , nine in period 4, twelve in period 5 and all 15 PHCs in periods 6 and 7. An independent epidemiologist generated the random allocation sequence without any stratification before start of the study, and kept it concealed from the study implementation team until the time of rolling out of the intervention in a PHC cluster.

The intervention consisted of activities designed to (1) build clinical care capacity of health providers through self-directed and facilitated exercises, (2) assess structure, processes and outcomes of the PHCs to identify quality gaps, and (3) provider teams undertaking improvement activities to close the identified quality gaps. These activities were carried out in form of (1) internal quality management activities in weekly 


\section{Quality management activities}

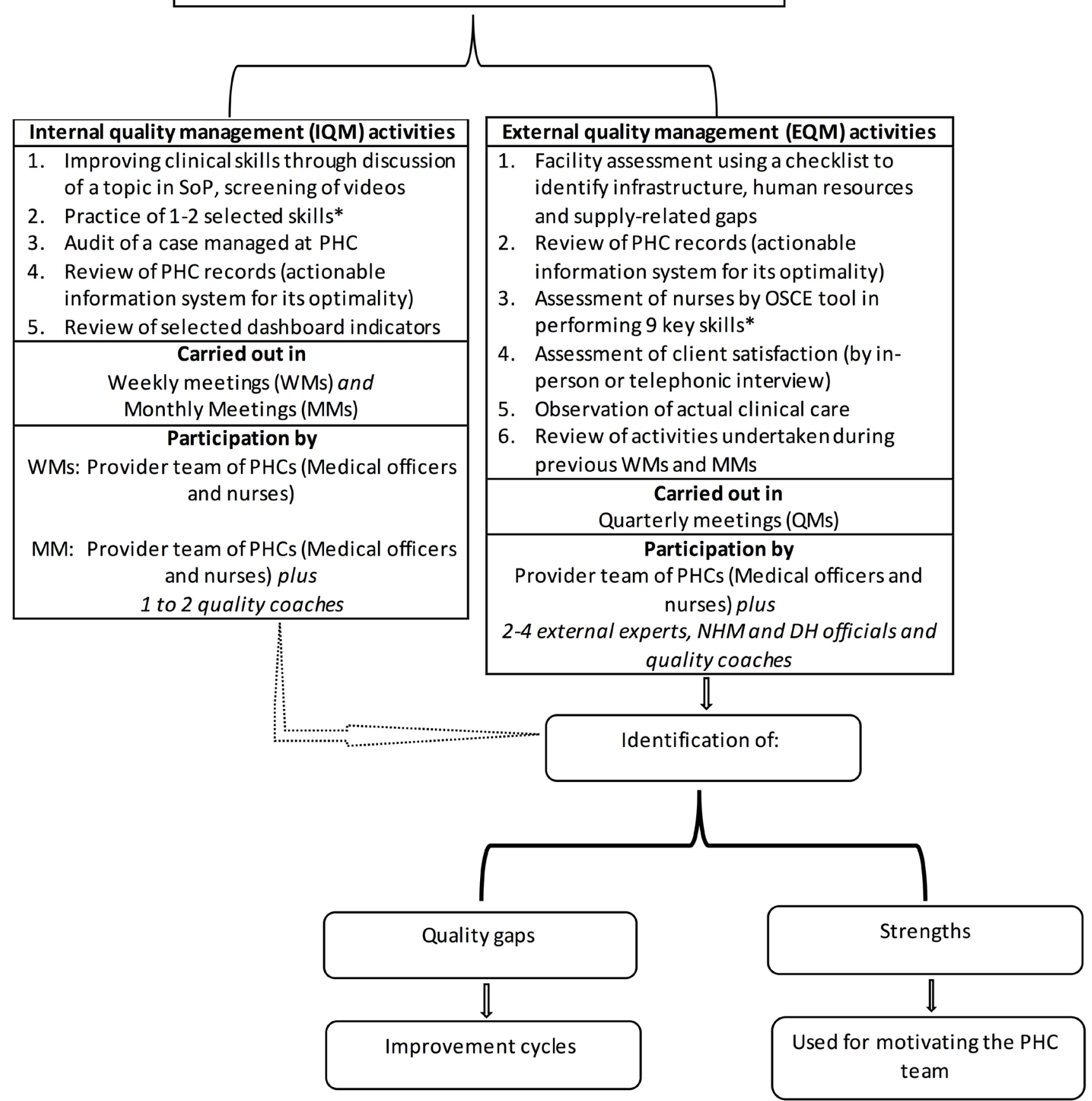

Figure 1 Conceptual diagram depicting activities during the intervention period. *Skills included those related to care women (general physical examination, obstetric examination, use of photograph and active management of third stage of labour), baby (measuring weight and axillary temperature, breast feeding support and detection of sickness) or both (hand hygiene). $\mathrm{DH}$, district hospital; NHM, National Health Mission; OSCE, Objective Structured Clinical Examination; PHC, primary health centre; SoP, standard operating procedure.

meetings (WM) and monthly meetings (MM), and (2) external quality management (EQM) activities in form of quarterly meetings $(\mathrm{QM})$. Figure 1 provides details of activities undertaken in WMs, MMs and QMs. In brief, in WMs, the provider team assembled for approximately 1 hour and discussed a topic from standard operating procedures $(\mathrm{SoP})$, practised a skill, screened a video on their smartphone, audited a case managed in their PHCs, reviewed PHC records and selected dashboard indicators. The study team specially prepared simple SoPs and collected available simple and brief videos pertaining to care during and after childbirth and referral care (online supplementary table S2). This resource material, based on prevailing WHO and Government of India guidelines, 
was supplied to the PHC teams. Every fourth WM (designated as MM) was facilitated by one to two quality coaches (a nurse and/or a general-duty physician) from the study team. Initially, it was planned that NHM staff would play the role of quality coach; however, due to limited capacity, the study team had to replace NHM for this job. The provider teams prepared a report of WMs and MMs and shared it with study team for feedback.

The EQM activities were carried out in place of every 12th WM (designated as QM). In these QMs, a study team visited the PHC typically for 4 hours. This team of at least two external experts, NHM and DH officials and the respective quality coach(es) (a total of four to five members) visited the PHCs. The external experts were drawn from the faculty of paediatrics, obstetrics and nursing from surrounding medical and nursing colleges. Sometimes, a management science expert also participated in the QMs. This team carried out structured assessment of the availability of physical and human resources, adequacy of supplies and functionality of equipment, key skills of the nurses and adequacy of case records. The team also performed a case audit and assessed client satisfaction by interviewing a couple of families present in the facility or managed in the past. The team witnessed QoC of clinical care actually being provided at the time of visit if there was an opportunity (eg, during childbirth) and also took stock of activities carried out in WMs and MMs (online supplementary table S2 provides tools used for the assessments). The team carried out assessment in a non-judgemental and cordial manner, encouraging the provider teams to share their achievements and frustrations and by appreciating their positive aspects. The team prepared a report on the strengths and weaknesses of the PHC and, together with the provider team, identified quality gaps and discussed ways to close the gaps in an ensuing debriefing meeting. The report was shared with NHM and DH administration for feedback and action.

The provider teams undertook improvement activities to close the quality gaps identified during different meetings. The NHM and/or DH officials participating in QMs were requested to assist in closing the gaps related to human and physical resources. The PHC staff learnt SoP, practised skills and discussed cases to close skill-related gaps. Records-related gaps were closed by education and encouragement. Additionally, as needdriven activities, study team designed structured case sheet containing partograph, discharge and referral cards, and postnatal monitoring chart for mother and baby for the PHCs. Client experience-related gaps were addressed by improving cleanliness and hygiene in the premises, improving communication skills of PHC staff and providing warm food to the admitted women.

\section{Outcomes}

The primary outcomes included number of women approaching PHCs for childbirth and 12 essential practices around the time of childbirth (total 13 primary outcomes; online supplementary table S3). We also measured several secondary outcomes related to the clients' experience of care and maternal and neonatal mortality and stillbirths (health outcomes).

We employed a robust system of outcome assessment. An independent outcome assessment team collected outcome data by deploying one research nurse per PHC who directly observed care provided around the time of childbirth. The outcome team did not share the outcome data with the study intervention implementing team, PHC staff or health administrators. The research nurse was not involved in clinical care. The research nurse tracked (telephonically or through home visits) all women presenting to PHCs for childbirth, irrespective of place of delivery and their babies, and recorded if they were alive or not on the 7th and 28th and 42nd days after delivery. For outcomes related to the directly observed 12 essential practices, women presenting to the PHC for childbirth were eligible for inclusion if the study observer could reach the PHC before delivery of the fetus.

We carried out verbal autopsy (VA) of all stillbirths, neonatal or maternal death. A team of paediatricians, nurses and social scientists reviewed the VA data and identified steps of referral, cause and place of death and if death could have been prevented. The death was classified as preventable if, in opinion of the VA team, optimum treatment could have prevented it.

Additionally, the study intervention team collected data on the gaps identified and gaps closed. A gap was defined as closed if it ceased to occur on any of subsequent QMs.

\section{Sample size calculation}

We used the method described by Hussey and Hughes for sample size calculation. ${ }^{18}$ A systematic review of primary care research that estimated intracluster correlation coefficient (ICC) for 1039 variables from 31 studies found a median ICC of 0.005 with IQR of $0-0.021 .^{19}$ To account for potentially large clustering effect in different practices in the set of three PHCs, we assumed a relatively larger value of ICC (0.1). Based on the existing records, we estimated that the prevalence of the key practices ranged from $10 \%$ (eg, skin-to-skin contact after delivery) to $75 \%$ (use of uterotonic agents for augmentation of labour, a harmful practice) at the study PHCs (online supplementary table S3). We hypothesised that with the intervention, the practices would improve by absolute percentage points of 10-15 in the intervention period. Assuming an ICC of 0.1 , we needed to observe 30 deliveries per cluster of three PHCs per period of 3 months to achieve a power of $80 \%$, and two-sided alpha value of $0.05 .{ }^{18}$

\section{Ethics and consent}

The institutional ethics committees of WHO-Geneva, All India Institute of Medical Sciences-New Delhi and Government Medical College-Chandigarh approved the study protocol. Written informed consent was sought from women who were observed for collection of information about the 12 essential practices and a standardised consent form was used for this process highlighting 
benefits, harms, role of participants, voluntary nature of participation and independence to withdraw. The information provided did not differ in the intervention and control arms and women did not know the 'arm' she was being recruited to. The study protocol was registered at CTRI.org (CTRI/2016/05/006963).

\section{Statistical analysis}

The data were captured in electronic case record form with in-built options of range check and cross-validation. The Global Positioning System capability of the handheld devices allowed us to track those data that were being recorded on the site and in real time. The outcome team monitored quality of data on an ongoing basis by cross-checking $10 \%$ data from PHC records and independently interviewing women. Data supervisor checked data for completeness and accuracy.

Data were expressed as proportions, mean and SDs, or median and IQR. The outcome of number of deliveries was expressed in terms of PHC-month. Generalised estimating equations-population-averaged model was used to adjust the effect size of primary outcomes with random effect for cluster (PHC) and fixed effect for the "calendar time'. To account for the possible lag in uptake of intervention, we assumed the first intervention period to be the 'lag-period' and observations during this lag period were considered under 'control period'. The analysis was two sided and by intention to treat. We did not make any correction for multiple comparisons. Data were analysed using Stata V.11.0 (StataCorp, USA).

Additionally, for three case studies presented in the Results section, we calculated a composite care score for each mother-baby dyad by scoring observed practices ( $1=$ done correctly; $0=$ not done correctly) and expressed it as proportion, with the numerator being addition of scores of all observed practices for a mother-baby dyad and denominator being best possible score.

\section{RESULTS}

Of the scheduled activities during the intervention period, $62 \%$ of WMs, $79 \%$ of MMs and $73 \%$ of QMs were conducted (online supplementary table S4). The PHC nurses participated more often than PHC MOs in the quality management activities (online supplementary table S4). At least two external experts, NHM and DH officials participated in QMs on 100\%, 43.2\% and 9.1\% occasions, respectively.

Of a large number of quality gaps $(n=479)$ identified during QMs, only $32.8 \%$ were closed successfully (table 1). Gaps related to human and physical resources and experience of care were less likely to be closed than

Table 1 Quality gaps identified during quarterly quality management meetings and their closure rates

\begin{tabular}{|c|c|c|}
\hline Nature of quality gap & $\begin{array}{l}\text { Gaps identified } \\
\mathbf{n}\end{array}$ & $\begin{array}{l}\text { Gaps closed } \\
\text { n ( } \% \text { of gap identified) }\end{array}$ \\
\hline Physical resources & 161 & $41(25.5)$ \\
\hline Infrastructure & 95 & $23(24.2)$ \\
\hline Functional equipment & 26 & $7(26.9)$ \\
\hline Supplies and consumables & 40 & $11(27.5)$ \\
\hline Provision of care & 117 & $42(35.9)$ \\
\hline Clinical care & 63 & $21(33.3)$ \\
\hline Routine intrapartum and postnatal care of mother & 29 & $7(24.1)$ \\
\hline Routine postnatal care of baby & 34 & $14(41.2)$ \\
\hline Referral care & 54 & $21(38.9)$ \\
\hline Detection and management of complications in mother & 22 & 7 (31.8) \\
\hline Detection and management of complications in baby & 9 & $4(44.4)$ \\
\hline Timely referral and prereferral stabilisation & 16 & $8(50)$ \\
\hline Communication and feedback from referring unit & 6 & $1(16.7)$ \\
\hline Provider accompanying the family & 1 & $1(100)$ \\
\hline Actionable information system & 89 & $35(39.3)$ \\
\hline Skills of health providers & 72 & $28(38.9)$ \\
\hline Experience of care & 20 & $4(20.0)$ \\
\hline Human resources & 11 & $1(9.1)$ \\
\hline Others (disbursement of JSY money, utilisation of JSSK funds, etc) & 9 & $6(66.7)$ \\
\hline Total & 479 & $157(32.8)$ \\
\hline
\end{tabular}

Values expressed as $\mathrm{n}$ or $\mathrm{n}(\%)$.

JSSK, Janani Shishu Suraksha Karyakaram (Government of India's programme to provide free treatment, food and transport facility to mother and her infant in public facilities in India); JSY, Janani Suraksha Yojana (conditional cash transfer scheme of Government of India). 


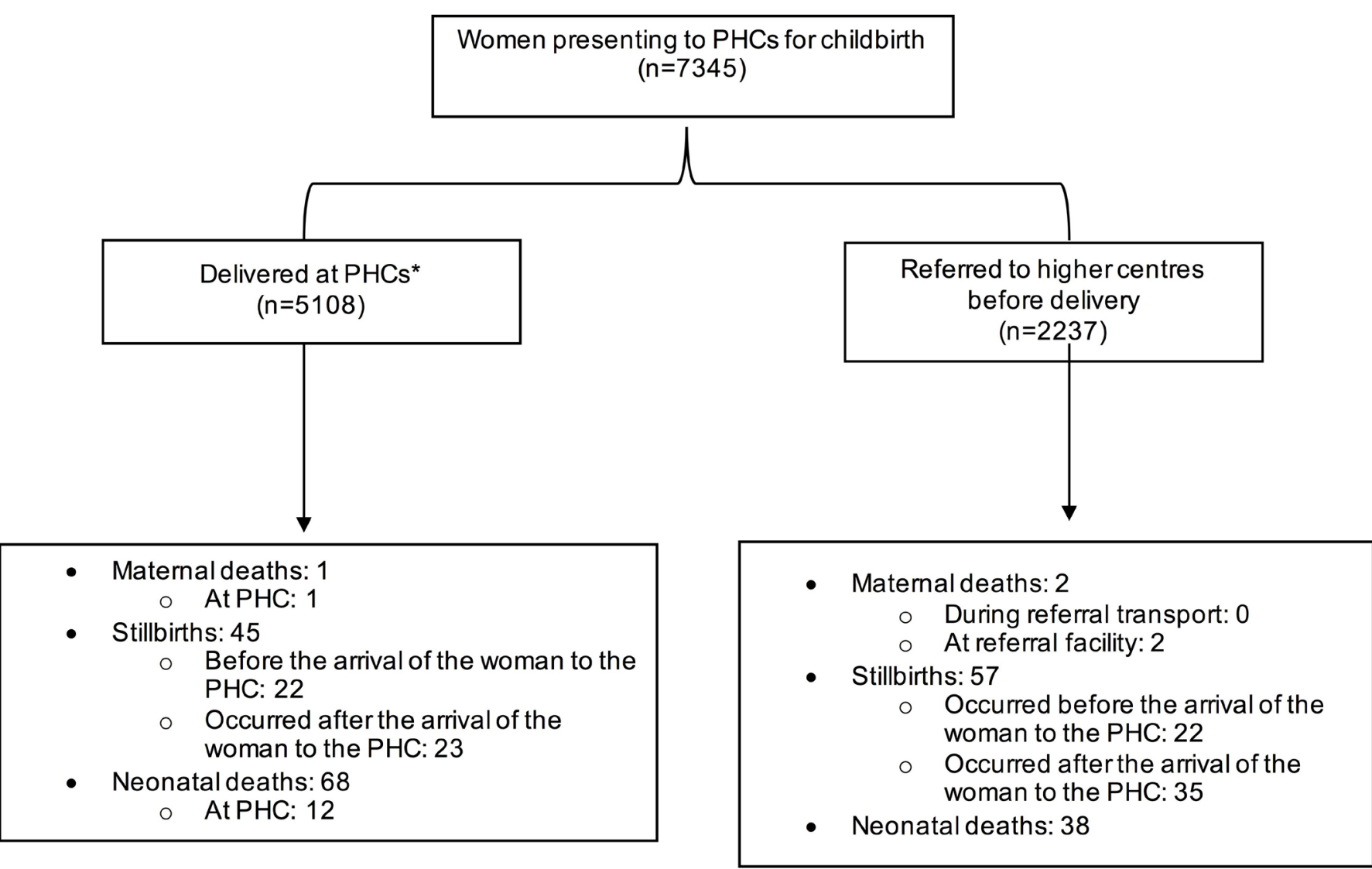

Figure 2 Study participant flow. *The women or the baby may have required referral after delivery. PHC, primary health centre.

those related to actionable information system, providers' skills and provision of care. In order to facilitate gap closure, the project team met NHM and district health administration (online supplementary table S5). Of the 20 action items identified during these meetings, five were successfully accomplished and another five could partially be accomplished. The items related to provision of uniform records could be undertaken successfully. However, the action points related to ensuring adequate strength of nurses and sanitation staff, round-the-clock availability of electricity and provision of extra budget could not be undertaken.

\section{Study outcomes}

Patient flow and their baseline characteristics

Of 7345 women approaching PHCs during the study period, 5108 delivered in the PHCs and 2237 were referred to higher centres before childbirth (figure 2, online supplementary figure S2). The research nurse observed care during and after childbirth of 1623 women and their babies during intervention period (median: 100 per PHC cluster per 3 months period, IQR: 75.5-130.5) and 1720 women and their babies during control period (median: 79.5 per cluster period, IQR: 72.8-96.5). The women were relatively young, with low level of education, poor and more from vulnerable social groups. There was not a large difference in women admitted to the PHCs in two periods except that a lower proportion of them belonged to underprivileged social classes in the intervention period (online supplementary table S6).

\section{Primary outcomes}

Table 2 shows the study primary outcomes. There was a 22\% increase in number of women approaching for childbirth to PHCs during intervention period.

Three of five key practices observed before childbirth improved in the intervention periods: hand hygiene before per-vaginal examination, recording of fetal heart rate and use of partograph. The practice of use of sterile gloves during per-vaginal examination remained unchanged while use of uterotonics for augmentation of labour (a harmful practice) was worsened. Among after childbirth practices, two of them, namely uterotonic use and early birth weight measurement, were almost universal in both the periods. Of the remaining five practices, skin-to-skin contact with the mother immediately after birth, discharge after 24 hours of birth and adequate discharge preparedness improved in the intervention period. Two practices remained unchanged: drying the baby immediately after birth and early initiation of breast feeding.

\section{Secondary outcomes}

Figure 2 shows the participant flow. Of 102 stillbirths, 44 (43.1\%) occurred before women arriving to the PHC. There was no difference in rates of maternal or neonatal 


\begin{tabular}{|c|c|c|c|c|}
\hline & $\begin{array}{l}\text { Intervention period } \\
(n=1623)\end{array}$ & $\begin{array}{l}\text { Control period } \\
(n=1720)\end{array}$ & $\begin{array}{l}\text { Adjusted OR/ } \\
\text { IRR }^{*} \\
(95 \% \mathrm{Cl})\end{array}$ & $P$ values \\
\hline $\begin{array}{l}\text { Women approached PHC for childbirth; } n \text { per } \\
\text { PHC-month }\end{array}$ & $\begin{array}{l}3514 / 135 \\
\text { (26 per PHC-month) }\end{array}$ & $\begin{array}{l}3831 / 180 \\
\text { (21 per PHC-month) }\end{array}$ & $\begin{array}{l}1.22 \dagger \\
(1.17 \text { to } 1.28)\end{array}$ & \\
\hline \multicolumn{5}{|l|}{ Practices before childbirth } \\
\hline $\begin{array}{l}\text { Hand hygiene before per-vaginal examination } \\
\text { on all occasions }\end{array}$ & $\begin{array}{l}695 / 1058 \\
(65.7)\end{array}$ & $\begin{array}{l}660 / 1269 \\
(52.0)\end{array}$ & $\begin{array}{l}1.47 \\
(1.13 \text { to } 1.90)\end{array}$ & 0.004 \\
\hline $\begin{array}{l}\text { Use of sterile gloves for per-vaginal } \\
\text { examination on all occasions }\end{array}$ & $\begin{array}{l}923 / 1263 \\
(73.1)\end{array}$ & $\begin{array}{l}1100 / 1340 \\
(82.1)\end{array}$ & $\begin{array}{l}0.91 \\
(0.67 \text { to } 1.22)\end{array}$ & 0.52 \\
\hline Fetal heart rate recording on all occasions & $\begin{array}{l}1125 / 1263 \\
(89.1)\end{array}$ & $\begin{array}{l}1070 / 1340 \\
(79.8)\end{array}$ & $\begin{array}{l}1.47 \\
(1.03 \text { to } 2.09)\end{array}$ & 0.03 \\
\hline $\begin{array}{l}\text { Use of partograph on all obstetric } \\
\text { examinations }{ }^{\star}\end{array}$ & $\begin{array}{l}535 / 1263 \\
(42.4)\end{array}$ & $\begin{array}{l}675 / 1340 \\
(50.4)\end{array}$ & $\begin{array}{l}1.63 \\
(1.28 \text { to } 2.07)\end{array}$ & $<0.0001$ \\
\hline Augmentation of labour using uterotonic ${ }^{\star}$ & $\begin{array}{l}160 / 1411 \\
(11.3)\end{array}$ & $\begin{array}{l}207 / 1567 \\
(13.2)\end{array}$ & $\begin{array}{l}1.77 \\
\text { (1.21 to } 2.58)\end{array}$ & 0.003 \\
\hline \multicolumn{5}{|l|}{ Practices after childbirth } \\
\hline $\begin{array}{l}\text { Use of uterotonic after delivery for active } \\
\text { management of third stage of labour }\end{array}$ & $\begin{array}{l}1432 / 1448 \\
(98.9)\end{array}$ & $\begin{array}{l}1426 / 1481 \\
(96.3)\end{array}$ & $\begin{array}{l}1.27 \\
(0.54 \text { to } 3.0)\end{array}$ & 0.58 \\
\hline $\begin{array}{l}\text { Placing the baby in skin-to-skin contact with } \\
\text { mother within } 1 \text { hour of birth }\end{array}$ & $\begin{array}{l}886 / 1431 \\
(61.9)\end{array}$ & $\begin{array}{l}670 / 1476 \\
(45.4)\end{array}$ & $\begin{array}{l}1.38 \\
(1.18 \text { to } 1.62)\end{array}$ & $<0.0001$ \\
\hline $\begin{array}{l}\text { Initiation of breast feeding within } 1 \text { hour of } \\
\text { birth }\end{array}$ & $\begin{array}{l}946 / 1331 \\
(71.1)\end{array}$ & $\begin{array}{l}756 / 1390 \\
(54.4)\end{array}$ & $\begin{array}{l}1.02 \\
(0.82 \text { to } 1.26)\end{array}$ & 0.86 \\
\hline Baby dried within 1 min of birth & $\begin{array}{l}647 / 1448 \\
(44.7)\end{array}$ & $\begin{array}{l}400 / 1478 \\
(27.1)\end{array}$ & $\begin{array}{l}1.27 \\
(0.99 \text { to } 1.63)\end{array}$ & 0.06 \\
\hline Birth weight recorded within 2 hours of birth & $\begin{array}{l}1384 / 1405 \\
(98.5)\end{array}$ & $\begin{array}{l}1412 / 1439 \\
(98.1)\end{array}$ & 1.49 (0.64 to 3.49$)$ & 0.35 \\
\hline Discharge after 24 hours after delivery & $\begin{array}{l}1103 / 1318 \\
(83.7)\end{array}$ & $\begin{array}{l}825 / 1353 \\
(61.0)\end{array}$ & 2.14 (1.60 to 2.88$)$ & $<0.0001$ \\
\hline Adequate discharge preparedness $\dagger$ & $\begin{array}{l}927 / 1165 \\
(79.6 \%)\end{array}$ & $\begin{array}{l}582 / 1249 \\
(46.6 \%)\end{array}$ & $\begin{array}{l}1.79 \\
\text { (1.41 to } 2.27)\end{array}$ & $<0.0001$ \\
\hline
\end{tabular}

Data expressed as $\mathrm{n}(\%)$ unless specified otherwise.

$\mathrm{PHC}$, primary health centre.

'The summary statistics is expressed as adjusted ORs for all practices except 'women approached PHC for childbirth' which was expressed in terms of incidence rate ratio (IRR). The data were adjusted for secular trend and cluster. As a result, for the practices 4 and 5 , despite having lower rates in intervention period than control period, adjusted ORs are in the opposite direction.

†Presence of all: exclusive breast feeding at discharge, women counselled and she is aware of danger signs for herself and her baby).

mortality or stillbirths between two periods (online supplementary table $\mathrm{S} 7$ ).

Of 171 deaths investigated by VA, $18(10.5 \%)$ happened during referral transport and $94(55.0 \%)$ at referral facilities. Forty per cent $(35 / 87)$ of neonatal deaths and $21.5 \%$ $(14 / 65)$ of fresh stillbirths experienced at least two steps of referral. Birth asphyxia was the most common ( $\mathrm{n}=99$, $58.6 \%$ ) cause of stillbirth and neonatal death followed by infection $(\mathrm{n}=18)$ and prematurity $(\mathrm{n}=18)$. Two maternal deaths and most of stillbirths or neonatal deaths $(83.4 \%$, $141 / 169)$ were deemed preventable through provision of good-quality antenatal, intrapartum and referral care.

\section{Challenges}

We noted several challenges to improvement efforts during the study. Decrease in state NHM budget (from US $\$ 0.85$ million in $2014-2015$ to US\$0.55 million in
2015-2016) led to substantial reduction in the strength of its supervisory staff (from 22 to 2) and decline in its participation in the intervention activities (from 17/21, $81.0 \%$ of QMs in the first half to $3 / 30,10 \%$ in the second half of study). The frequent changes in leadership at state level (two changes in state health secretary, one change in director, Mother and Child Health), in NHM (two changes in mission director) and at DH (two changes in chief MO in one) in second half of the study led to fragility of the health system. The transfer out of nurses to other health facilities influenced the optimum functioning of PHCs (case study, vide infra). Most PHC nurses were contract job worker $(51 / 60 ; 85 \%)$ getting approximately $40 \%$ of the monthly salary as compared with nurse in the regular job (US\$; 140 vs 400). PHC MOs had multiple job responsibilities within and outside 
PHCs (mandatory jail duty, night duties at community health centre (CHC), additional responsibilities at $\mathrm{DH}$, multiple trainings within and outside PHC) limiting their focus on childbirth services at their own PHC. Nine of 15 PHCs did not have female MO for a period of at least 3 months during the study period. None of the PHCs had deployment of sanitary or security staff and the PHC staff had to make adhoc arrangement for these services. The other significant challenges included prolonged and regular power outages (up to 16-18 hours for most PHCs) with inadequate/non-existent power backup, no provision for fresh and warm food for mothers, delay in availability of ambulances, suboptimal system of supply of essential drugs resulting in local purchases and lack of uniformity of records.

\section{Case studies}

Most of the PHCs showed improvement in key practices related to childbirth during the study. However, contextual factors such as local leadership, adequate availability of human resources and incidental activities influenced the effect of intervention. We illustrate three case studies highlighting such influences (Box 1 and figure 3). In the first case study, a poorly performing PHC showed significant improvement due to strong leadership of the $\mathrm{MO}$ in charge. In the second case study, QoC declined due to transfer out of three of the five nurses from a high case load PHC. In the third case study, an already well-performing PHC deteriorated following a maternal death.

\section{DISCUSSION}

The intervention strategy in our study has shown a modest effectiveness: increase in number of deliveries signifying improved utilisation of $\mathrm{PHC}$ and modest improvement of 6-12 key practices. There was no suggestion of any change either in stillbirth or neonatal mortality rates (secondary outcomes). Importantly, the study highlights two very important issues with serious implication to future research and policy: (1) despite substantial strengthening of the public health system in past two decades, there exists a significant degree of fragility and weakness at all levels potentially undermining any improvement efforts; (2) a majority of stillbirths and neonatal deaths occurred in women and their babies during referral transport or at the referral facilities.

Five randomised controlled studies have investigated impact of interventions to improve QoC at the time of childbirth at PHCs. ${ }^{20-25}$ Taking cues from the evidence of efficacy of use of the surgical checklist in settings of strong health systems, the BetterBirth study focused on providers using a checklist tool to improve essential practices during childbirth and reduce mortality in settings of weak health systems (Uttar Pradesh, India). The study intervention was limited to providing intense coaching (43 visits in 8 months) to the facility staff for use of the checklist for improving the uptake of life-saving practices and did not specifically focus on strengthening of the

\section{Box 1 Case studies}

\section{Case study 1}

PHC A, located $12 \mathrm{~km}$ away from the district headquarter, had deployment of one to five nurses and two MOs during the study period. This PHC was one of the poorly performing PHCs and it initiated intervention in the fourth month of the study. Motivated by the quality management process, the $\mathrm{M} 0$ in charge provided exceptional leadership to the team resulting in significant improvement in the $\mathrm{PHC}$ performance over the remaining study period (figure 3 ). The number of deliveries increased from an average of 6 per month in the control period to 17 per month in the intervention period. There was a significant improvement in composite care score. The M0 in charge took keen interest in the quality management activities by supervising the work of nurses, closing gaps in the staff deployment by interacting with district hospital administration. The PHC added an extra labour table, constructed a toilet in labour room and put up curtains in postnatal ward to ensure privacy.

Case study 2

PHC B, located in a township, had two MOs including one female $\mathrm{MO}$, two to five nurses and adequate physical infrastructure. The PHC initiated intervention in the 15th month of the study. It had a high case load (average 36 deliveries per month) during the study period. The composite care score of the PHC was high indicating good performance of the PHC during initial 12 months. At 12 months, there were major changes in the deployment of health providers in the PHC: reduced strength of nurses (from five to two) due to transfer of three nurses and the additional responsibility given to the $\mathrm{MO}$ at the DH making him unavailable for good part of his time for the PHC. As a result, there was a significant decline in composite care score in ensuing months (figure 3). The two nurses were unable to deliver optimum childbirth services due to excessive workload and the MO was not able to provide leadership to the PHC team. There was inadequate uptake of quality management activities when intervention started at the PHC from the 15th month of the study.

Case study 3

PHC C, located about $11 \mathrm{~km}$ away from the district headquarter, had one to two MOs including a female MO and two to five nurses during the study period. The PHC had labour room and postnatal care facilities as per the state norms. This PHC initiated intervention in the fourth month of the study. The MO in charge was a motivated and committed person and led the team to provide good services with a large number of deliveries ( $n=15$ per month) occurring in the PHC. During the 11th month of study, a maternal death occurred, which led to an enquiry by the district administration. The M0 got intimidated and proceeded on leave. Thereafter, she was irregular and distracted from her work. The staff got demoralised and the community behaved in a hostile manner. The number of deliveries declined. Quality management team made persistent efforts to raise the morale of the staff and continued to visit the PHC and interact with staff. The MO resumed work only after about 4 months and there was improvement in services thereafter.

$\mathrm{DH}$, district hospital; M0, medical officer; PHC, primary health centre.

health system or provider skills. While the study did find a modest improvement in the practices $(73 \%$ in intervention arm vs $42 \%$ in the control arm) with use of checklist at 4 months of intervention, there was no effect on the perinatal death, maternal deaths and maternal severe complications. Also, the improvement in practices too 

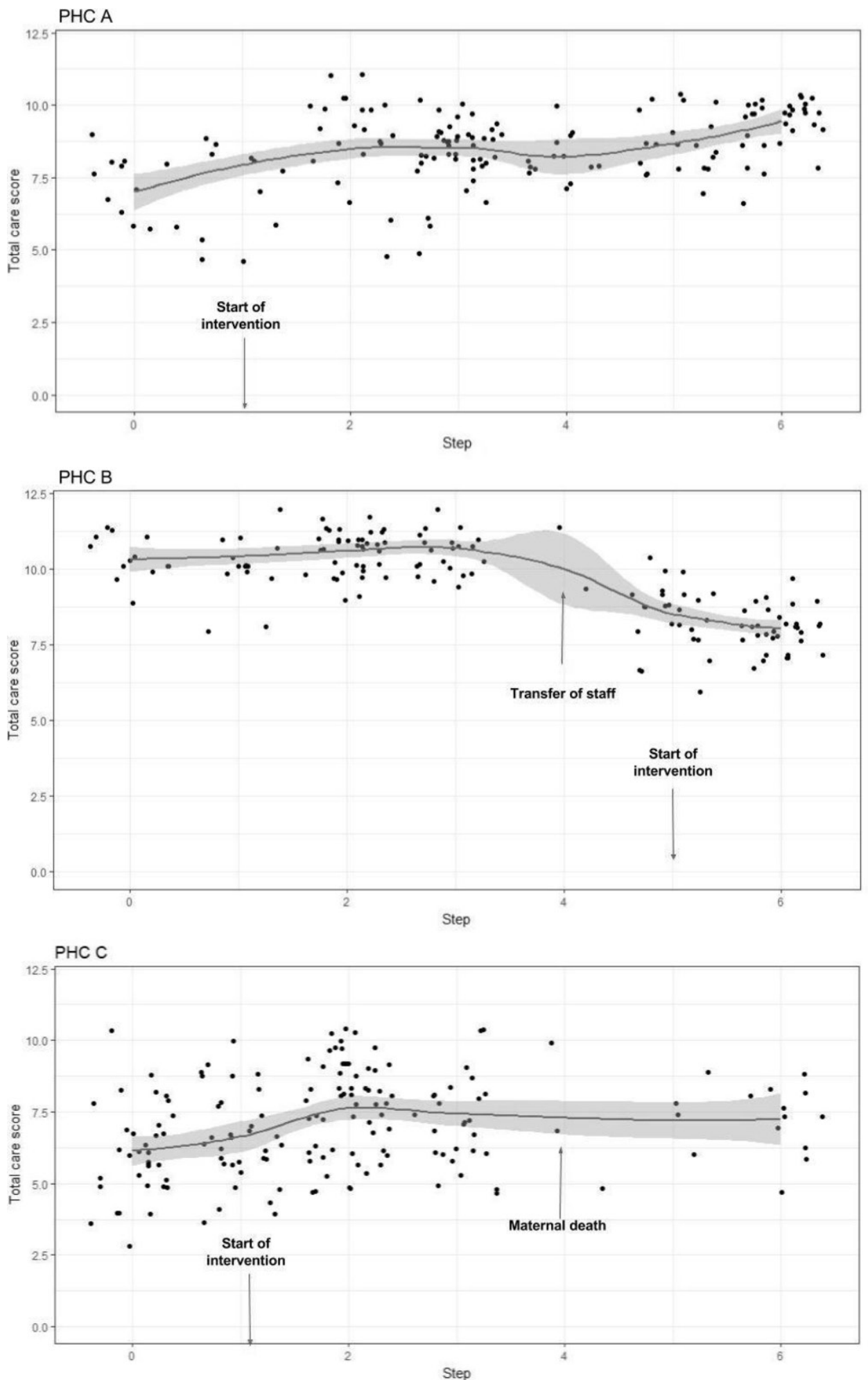

Figure 3 Performance of three primary health centres (PHC). Y-axis represents the care score derived from adding the number of 12 childbirth practices received by a patient. Dots represent the care score of individual observed patient. Solid line with shaded area represents the smoothed trend in care score and its $95 \% \mathrm{Cl}$.

dwindled in a few months of cessation of the intervention. Unfortunately, this study did not provide concrete data as to why the intervention was modestly effective in improving practices and did not improve mortality and other health outcomes. A study with factorial design from Malawi showed no reduction in neonatal and perinatal mortality with improvement intervention at facility level unless it was combined with community mobilisation. ${ }^{20}$ There was $22 \%$ reduction in neonatal mortality with combined facility and community intervention and $16 \%$ reduction in perinatal mortality with community intervention alone. Another cluster-randomised trial in 
PHCs of India reported improved provider preparedness, facility readiness to deal with childbirth and related complications, and improved practices as reviewed from records. ${ }^{22}$

Our study focused on a multipronged approach targeted at improvement of all the important pillars of the health systems and systematically measured the existing gaps in health systems and barriers to quality improvement. The facility staff drove the improvement process with external mentoring and with the involvement of government functionaries. Though our study results are in agreement with BetterBirth study, it provides deeper insight as to why improvement efforts in these two important studies may not have yielded the expected results and what could be the way forward to improve the QoC and health outcomes in small facilities.

Our study reinforces the WHO notion, which is based on Donabedian model, that provision of optimum QoC requires existence of a robust health system including leadership/governance, accountability, adequate financing, skilled and committed human resource and physical resources. ${ }^{6}{ }^{12}$ The improvement processes in our study identified a large number of serious gaps $(n=479)$ in almost every essential domain of the health system. Moreover, low level of motivation and a lower level of accountability, and vulnerability of the health systems to a variety of contextual factors further hindered the improvement process. Many of identified gaps $(\mathrm{n}=322 / 479,67.2 \%)$ could not be closed despite multiple improvement activities, undertaken by the facility staff and efforts made by the project team as these required concrete actions at the higher level of health system, which was also seriously limited. The effective closure of gaps in skills requires a high level of motivation for learning of the providers as well as availability of enough opportunities for honing of the skills. For effective functioning of the PHCs, we feel multiple factors have to be addressed that include but not limited to health systems made more resilient by ensuring stability of the leadership, easy fund flow, the issue of availability of skilled and motivated providers and creating a framework of accountability at all levels. There is a need to explore if the available resources can be used in a more efficient manner-likely strengthening of better performing PHCs and downscaling low-volume PHCs. While the governments and policymakers are understandably looking for the scalable models of improving QoC that work in the health system with all its weaknesses, our study strongly highlights the need to have stronger, accountable and responsive health system as an essential prerequisite for significant improvement in QoC at health facilities. In our study, implementation of the intervention package was led by PHC healthcare workers with periodic external facilitation. More intensive support or mentoring by EQM teams could have made more impact on the study outcomes. However, sustainability of improvement achieved by such an approach has not been demonstrated. ${ }^{11}$ Large number of gaps in healthcare infrastructure identified in the study indicates the intervention package should have stronger quality assurance component.

PHCs cater to low-risk conditions. Linking these institutions to referral facilities through optimal referral transport is critical to improve health outcomes of its clients. But, this critical link is often not as effective as it should be. There are delayed recognitions of conditions requiring referral and suboptimal transport (second delay) and significant third delay in overburdened referral facilities. VA data revealed that 49 of 152 stillbirths or neonatal deaths, families had to visit at least two referral facilities for the want of care. Nearly two-thirds (112/171) of deaths occurred in patients during referral transport or at referral facilities. A large number of stillbirths occurred even before women presenting to the PHC highlighting a poor quality of antenatal care including optimum counselling of women to recognise danger signs. In face of existence of such critical weakness in the health system, the bad outcomes cannot be effectively averted no matter how good QoC is provided at the smaller facilities. It is therefore imperative that the QoC programmes target improvement of services at all levels starting from first contact facilities to the referral centres.

Our study has several limitations. It was a small study involving only 15 PHCs with relatively low case load in two districts and not powered for mortality and other important health outcomes. As the perinatal, neonatal and maternal mortality outcomes can only be influenced if a range of services (processes) are improved, we took 13 outcomes to be studied as the primary outcomes. We calculated the sample size for each of these 13 practices and took the largest sample size. However, the analysis does not account for multiple hypotheses testing. The primary outcome of number of deliveries depended on several other factors apart from QoC but we believe that study design addressed this issue. The study investigators could not have blinded. However, we employed robust independent outcome measurement. We did not evaluate costing and the sustainability of the model. Lastly, the SW design does not fully compensate for secular trend but is a design of choice for such interventions. The effect of contextual factors on the success of QM approach was demonstrated by three different case studies. However, this before-and-after analysis does not preclude the potential effect of secular trend.

In conclusion, our study reports modest effectiveness of a quality management strategy driven by the provider teams with external facilitation in small health facilities of Haryana, India. We noted several serious and difficultto-close quality gaps in the health system as the limiting factors for desirable level of improvement in QoC and potentially health outcomes. Two-thirds of deaths occurred in women and their babies during the transport or at the referral facilities. We recommend that a stronger and functional health system and a responsive and accountable mechanism to identify and effectively close the quality gaps in health system must be an integral part of any QoC programmes. 


\section{Author affiliations}

${ }^{1}$ Division of Neonatology, Department of Pediatrics, All India Institute of Medical Sciences, New Delhi, India

${ }^{2}$ Department of Neonatology, Government Medical College Hospital, Chandigarh, India

${ }^{3}$ Survival for Women and Children Foundation (SWACH), Panchkula, India

${ }^{4}$ Saha Manthran Pvt Ltd, Gurugram, India

${ }^{5}$ National Health Mission (Haryana), Government of India, Panchkula, India

${ }^{6}$ Maulana Azad Medical College and LNJP Hospital, New Delhi, India

${ }^{7}$ Department of Obstetrics and Gynecology, Government Medical College Hospital, Chandigarh, India

${ }^{8}$ National Institute of Malaria Research, New Delhi, India

${ }^{9} \mathrm{Pt}$ BD Sharma PGIMS, Rohtak, India

${ }^{10} \mathrm{PGIMER}$, Chandigarh, India

${ }^{11} \mathrm{MM}$ College of Nursing, Mullana, Ambala, India

${ }^{12}$ Department of Biostatistics, All India Institute of Medical Sciences, New Delhi, India

${ }^{13}$ Safadarjung Hospital and Vardhman Mahavir Medical College, New Delhi, India

${ }^{14}$ Government Medical College, Kannauj, India

${ }^{15}$ Swami Dayanand Hospital, New Delhi, India

${ }^{16}$ Western Command Hospital, Panchkula, India

${ }^{17}$ Santosh Medical College, Gaziabad, India

${ }^{18}$ UNICEF Rajasthan, Jaipur, India

${ }^{19}$ UNICEF Chhattisgarh, Raipur, India

${ }^{20}$ Lady Hardinge Medical College, New Delhi, India

${ }^{21}$ WHO, Geneva, Switzerland

Collaborators We are grateful to the study coinvestigators, and the implementation and management teams, including: Mamta Jajoo, MD; Vinay Kulkarni, Neeraj Gupta, DM; Anju Huria, MS; Levis Murry, Prahlad Agarwal, Herbaksh Kaur, Amit Duggal, Jaidev Khatri, Vinod Gupta, Mangat Ram Passi, VP Mann, Alaknanda Malik, Bela Jain, VK Jain, Deepshikha Sharma.

Contributors Writing committee: RA, DC, VK, VKP, RB. Investigators: NHM, Haryana: RG, SK, SKD, KJ, AS, SS, AD (NHM), JK; SWACH, Chandigarh: VK, PM, MS; AllMS, New Delhi: VKP, RA, SC, MJS, AT, VS, CPY; GMCH, Chandigarh: DC, ST, SJ; Saha Manthran, Gurugram, Haryana: SN, PA; Maulana Azad Medical College, New Delhi: KA; PGIMER, Chandigarh: PK; PGIMS, Rohtak: GG, KB; MM College of Nursing, Mullana, Ambala: JS, YK; WHO, Geneva: RB. Protocol development: VKP, VK, RB, DC, MJS. Study implementation: VK, PM, MS, Gagandeep, DS. Study resources development: SC, VKP, VK, AT, KA, RA, DC, MJS, RB. Study data team: DC. Study external facilitation team: RA, VPM, SC, SN, Shikha Taneja, KA, AT, GG, PK, JS, SJ, KCA, Yogesh Dhankar, PK, SSB, GS, RA, PD, RS, RY, KB, RB. Data analysis: MJS, RB, DC, VK, RA, VKP, CPY, VS

Funding The study was funded through a grant to the WHO by USAID. The WHO team participated in the protocol development, and provided technical support to the investigators in implementation, analysis of data, interpretation of findings and preparation of the manuscript. The corresponding authors had full access to all the data in the study and bear the final responsibility for deciding about the publication.

Disclaimer RB is a staff member of the World Health Organization. The expressed views and opinions in this paper do not necessarily express the policies of the World Health Organization.

Competing interests None declared.

Patient consent Obtained.

Ethics approval The institutional ethics committees of the World Health Organization, All India Institute of Medical Sciences and the Government Medical College, Chandigarh.

Provenance and peer review Not commissioned; externally peer reviewed.

Data statement The deidentified dataset is available upon request.

Open access This is an open access article distributed in accordance with the Creative Commons Attribution Non Commercial (CC BY-NC 4.0) license, which permits others to distribute, remix, adapt, build upon this work non-commercially, and license their derivative works on different terms, provided the original work is properly cited, appropriate credit is given, any changes made indicated, and the use is non-commercial. See: http:// creativecommons.org/licenses/by-nc/4.0/

\section{REFERENCES}

1. Liu L, Oza S, Hogan D, et al. Global, regional, and national causes of under-5 mortality in 2000-15: an updated systematic analysis with implications for the Sustainable Development Goals. Lancet 2016;388:3027-35.

2. GBD 2015 Maternal Mortality Collaborators. Global, regional, and national levels of maternal mortality, 1990-2015: a systematic analysis for the Global Burden of Disease Study 2015. Lancet 2016;388:1775-812.

3. GBD 2015 Child Mortality Collaborators. Global, regional, national, and selected subnational levels of stillbirths, neonatal, infant, and under-5 mortality, 1980-2015: a systematic analysis for the Global Burden of Disease Study 2015. Lancet 2016;388:1725-74.

4. Baqui $A H$, Mitra DK, Begum N, et al. Neonatal mortality within 24 hours of birth in six low- and lower-middle-income countries. Bull World Health Organ 2016;94:752-8.

5. Lawn JE, Blencowe $H$, Waiswa $P$, et al. Stillbirths: rates, risk factors, and acceleration towards 2030. Lancet 2016;387:587-603.

6. Tunçalp Ö, Were WM, MacLennan C, et al. Quality of care for pregnant women and newborns-the WHO vision. BJOG 2015;122:1045-9.

7. 2017. National Family Health Survey. http://rchiips.org/NFHS/ factsheet_NFHS-4.shtml (accessed 8 May 2017).

8. Powell-Jackson T, Mazumdar S, Mills A. Financial incentives in health: New evidence from India's Janani Suraksha Yojana. J Health Econ 2015;43:154-69.

9. Chaturvedi S, De Costa A, Raven J. Does the Janani Suraksha Yojana cash transfer programme to promote facility births in India ensure skilled birth attendance? A qualitative study of intrapartum care in Madhya Pradesh. Glob Health Action 2015;8:27427.

10. Bhutta ZA, Salam RA, Lassi ZS, et al. Approaches to improve Quality of Care (QoC) for women and newborns: conclusions, evidence gaps and research priorities. Reprod Health 2014;11(Suppl 2):S5.

11. Semrau KEA, Hirschhorn LR, Marx Delaney M, et al. Outcomes of a coaching-based WHO safe childbirth checklist program in India. N Engl J Med 2017;377:2313-24.

12. Donabedian $A$. The quality of care. How can it be assessed? JAMA 1988;260:1743-8.

13. 2017. Per Capita National Income. http://pib.nic.in/newsite/ PrintRelease.aspx?relid=123563 (accessed 12 Feb 2017).

14. 2017. Census of India : Sample Registration System. http://www. censusindia.gov.in/2011-Common/Sample_Registration_System. html (accessed 12 Feb 2017)

15. Open Government Datadp.awasthi, 2017. Trends in Under Five Mortality Rates - India and Bigger States. (OGD) Platform India 2013. Available from: https://data.gov.in/catalog/trends-under-fivemortality-rates-india-and-bigger-states [accessed 12 Feb 2017].

16. Sonkusare A, 2017. Below Poverty Line in India. Open Government Data (OGD) Platform India. 2014. https://data.gov.in/catalog/belowpoverty-line-india (accessed 12 Feb 2017).

17. Hemming K, Haines TP, Chilton PJ, et al. The stepped wedge cluster randomised trial: rationale, design, analysis, and reporting. BMJ 2015;350:h391.

18. Hussey MA, Hughes JP. Design and analysis of stepped wedge cluster randomized trials. Contemp Clin Trials 2007;28:182-91.

19. Adams G, Gulliford MC, Ukoumunne OC, et al. Patterns of intracluster correlation from primary care research to inform study design and analysis. J Clin Epidemiol 2004;57:785-94.

20. Colbourn T, Nambiar B, Bondo A, et al. Effects of quality improvement in health facilities and community mobilization through women's groups on maternal, neonatal and perinatal mortality in three districts of Malawi: MaiKhanda, a cluster randomized controlled effectiveness trial. Int Health 2013:5:180-95.

21. Brown H, Hofmeyr GJ, Nikodem VC, et al. Promoting childbirth companions in South Africa: a randomised pilot study. BMC Med 2007:5:7.

22. Jayanna K, Bradley J, Mony P, et al. Effectiveness of onsite nurse mentoring in improving quality of institutional births in the primary health centres of high priority districts of karnataka, south india: A cluster randomized trial. PLoS One 2016;11:e0161957.

23. Namazzi G, Waiswa $P$, Nakakeeto $M$, et al. Strengthening health facilities for maternal and newborn care: experiences from rural eastern Uganda. Glob Health Action 2015;8:24271.

24. Jennings L, Yebadokpo A, Affo J, et al. Use of job aids to improve facility-based postnatal counseling and care in rural Benin. Matern Child Health J 2015;19:557-65

25. Jennings L, Yebadokpo AS, Affo J, et al. Antenatal counseling in maternal and newborn care: use of job aids to improve health worker performance and maternal understanding in Benin. BMC Pregnancy Childbirth 2010:10:75 